\title{
Phytochemical Study and Antibacterial and Antibiotic Modulation Activity of Punica granatum (Pomegranate) Leaves
}

\author{
Amine Trabelsi (D), ${ }^{1,2}$ Mohamed Amine El Kaibi, ${ }^{3}$ Aïmen Abbassi (iD, ${ }^{2}$ Amira Horchani, ${ }^{1,2}$ \\ Leila Chekir-Ghedira, ${ }^{2}$ and Kamel Ghedira ${ }^{1,2}$ \\ ${ }^{1}$ Pharmacognosy Laboratory, Faculty of Pharmacy, University of Monastir, Avicenna Street, Monastir 5000, Tunisia \\ ${ }^{2}$ Research Unit of Bioactive and Natural Substances and Biotechnology UR17 ES49, Faculty of Dental Medicine, \\ University of Monastir, Avicenna Street, Monastir 5000, Tunisia \\ ${ }^{3}$ Drug Development Laboratory (LR12ES09), Unit of Pharmacology, Faculty of Pharmacy, University of Monastir, \\ Avicenna Street, Monastir 5000, Tunisia \\ Correspondence should be addressed to Amine Trabelsi; trabelsi.amine13@gmail.com
}

Received 20 August 2019; Accepted 29 February 2020; Published 31 March 2020

Academic Editor: Katsumi Doi

Copyright (C) 2020 Amine Trabelsi et al. This is an open access article distributed under the Creative Commons Attribution License, which permits unrestricted use, distribution, and reproduction in any medium, provided the original work is properly cited.

\begin{abstract}
This study aimed to determine phytochemical contents, antibacterial properties, and antibiotic modulating potential of Punica granatum leaf extracts: hexane, chloroform, ethyl acetate, ethanol, and aqueous extracts as well as an extract enriched with total oligomer flavonoids (TOFs). The TOF extract contained the highest value of phenols and flavonoids. Rutin, luteolin, gallic acid, and ellagic acid were determined by HPLC analysis of this extract. The antibacterial activity was assayed by the disc diffusion method and microdilution method against Staphylococcus aureus and Escherichia coli standard ATCC strains and clinical isolates resistant strains. The TOF extract was the most active against all tested strains. The checkerboard method was used for the determination of synergy between two antibiotics (amoxicillin and cefotaxime) and P. granatum leaf extracts. The best synergistic interaction was found with TOF extract combined with amoxicillin for penicillin-resistant $E$. coli and penicillin-resistant $S$. aureus. These results can be assigned to tannins, flavonoids, and phenolic acids found in P. granatum leaf extracts. Pomegranate leaf extracts or active compounds isolated from these extracts could be used to fight the emergence and spread of resistant bacterial strains.
\end{abstract}

\section{Introduction}

According to the 2014 report of the World Health Organization (WHO), antimicrobial resistance is an increasingly serious public health issue that is reaching alarming levels. The emergence of multidrug-resistant bacteria makes antimicrobial treatments ineffective, lengthens the duration of illness and the time of hospitalization, and increases the mortality rate [1]. One of the solutions is the combination of antibiotics and other agents in order to have a synergistic effect. Many projects aim at developing a new generation of phytopharmaceuticals which can be used alone or in combination with antibiotics. This new generation of phytopharmaceuticals could lend phytotherapy a new legitimacy and it can give the possibility of treating diseases classically treated with synthetic drugs [2].

Punica granatum L. commonly known as pomegranate is a small tree of the family of Lythraceae. It is native from Persia and has been cultivated extensively in the Mediterranean countries such as Tunisia, Turkey, Egypt, and Spain and to some extent also in California, China, Japan, and Russia [3]. Constituents of $P$. granatum have been involved in many different biological and pharmacological activities. It has been observed that the phenolics contained in pomegranate leaves predominantly contributed to their health benefits. These phenolics possess a strong binding ability to different molecular structures like proteins or glycoproteins that can antagonize bacterial resistance [2]. 
Hence, this study aimed to determine phytochemical contents, antibacterial properties, and antibiotic modulation potential of six different pomegranate leaf extracts.

\section{Material and Methods}

2.1. Plant Material. The leaves of P. granatum (Gabsi cultivar) were collected from the region of Gabes situated in the South of Tunisia, in September 2015. A voucher specimen (Herbarium 23/2015) has been kept in the laboratory of pharmacognosy (Faculty of Pharmacy of Monastir, Tunisia) for future reference. The leaves were shade dried, powdered, and stored in a tightly closed container for further use.

2.2. Preparation of Plant Extracts. Hexane, chloroform, ethyl acetate, and ethanol extracts were obtained by successive Soxhlet extraction $(6 \mathrm{~h})$. These four extracts, with increasing polarities, were concentrated to dryness and kept at $4^{\circ} \mathrm{C}$.

The aqueous extract was prepared by a decoction of $50 \mathrm{~g}$ of plant material in $500 \mathrm{~mL}$ of boiling water for 20 minutes. After filtration, the extract was lyophilized and kept at $4^{\circ} \mathrm{C}$.

The extract enriched with total oligomer flavonoids (TOFs) was obtained, as described by [4], by maceration in a mixture of acetone/water $(2 \mathrm{~V} / 1 \mathrm{~V})$. After filtration, the acetone was evaporated under reduced pressure and the residual aqueous phase was saturated with $\mathrm{NaCl}$. The formed precipitate overnight at $4^{\circ} \mathrm{C}$ was removed by filtration. Liquid-liquid extraction was carried out with ethyl acetate. The organic phase was concentrated under reduced pressure and then poured into an excess of chloroform. The resulting flocculate corresponds to the TOF.

For phytochemical study and antibacterial and antibiotic modulation assays, each extract was dissolved in the adequate solvent. The same solvent was used in the corresponding negative control.

\subsection{Phytochemical Study}

2.3.1. Preliminary Phytochemical Screening. Extracts were screened for the presence of secondary metabolites such as tannins, flavonoids, saponins, cardiac glycosides, anthocyanins, and alkaloids. The secondary metabolites were detected qualitatively by the characteristic color changes occurring upon treatment with specific reagents [5].

2.3.2. Determination of Total Contents of Phenols, Flavonoids, and Tannins. The total content of phenols of extracts from $P$. granatum was determined by the Folin-Ciocalteau method [6]. Indeed, to $100 \mu \mathrm{L}$ of a solution of extract, $2 \mathrm{~mL}$ of sodium carbonate $\left(\mathrm{Na}_{2} \mathrm{CO}_{3}\right)$ at $2 \%$ and $0.1 \mathrm{~mL}$ of FolinCiocalteu reagent at 50\% were added. After incubation for 30 minutes at room temperature, a petroleum blue color indicates the presence of polyphenols which were measured at the wavelength of $720 \mathrm{~nm}$. Gallic acid was used as a standard, and results were expressed as milligram of gallic acid equivalents (GAEs) per gram of dry mass (DM).

The content of flavonoids of each extract was determined by the aluminum chloride colorimetric method [7]. This method consists in adding $75 \mu \mathrm{L}$ of $5 \% \mathrm{NaNO}_{2}, 150 \mu \mathrm{L}$ of $10 \% \mathrm{AlCl}_{3}$, and finally $500 \mu \mathrm{L}$ of $1 \mathrm{~N} \mathrm{NaOH}$ to $250 \mu \mathrm{L}$ of a solution of leaf extract. The volume was adjusted to $2.5 \mathrm{~mL}$ and incubated for 5 minutes at room temperature. Absorbance was measured at $510 \mathrm{~nm}$. Quercetin was used as a standard and results were expressed as milligram of quercetin equivalents (QEs) per gram of DM.

The content of tannins was determined by the FolinDenis [8]. We added $10 \mu \mathrm{L}$ of Folin-Denis reagent to $50 \mu \mathrm{L}$ of extract, followed by $25 \mu \mathrm{L}$ of saturated sodium carbonate solution, which was then incubated at room temperature for 90 minutes. The absorbance was measured at $760 \mathrm{~nm}$. Tannic acid was used as standard and results were expressed as milligram of tannic acid equivalents (TAEs) per $100 \mathrm{~g}$ of DM.

2.3.3. HPLC Characterization of TOF Extraction. A highperformance liquid chromatographic method with gradient elution and diode-array detection was used to quantify some phenolic acids (gallic acid, ellagic acid) and flavonoids (rutin, luteolin) in TOF extract.

HPLC analyses were performed with Shimadzu LC-2030 3D Plus (Prominence-i) chromatograph. The mobile phase contains $1 \%$ aqueous acetic acid solution (solvent A) and acetonitrile (solvent $\mathrm{B}$ ), the flow rate was adjusted to $0.7 \mathrm{~mL} /$ min, the column was thermostatically controlled at $28^{\circ} \mathrm{C}$, and the injection volume was kept at $10 \mu \mathrm{L}$. Gradient elution was performed by varying the proportion of solvent $\mathrm{B}$ to solvent A: from $10 \%$ to $40 \%$ B for $28 \mathrm{~min}$, from 40 to $60 \% \mathrm{~B}$ for $39 \mathrm{~min}$, and from 60 to $90 \% \mathrm{~B}$ for $50 \mathrm{~min}$. The mobile phase composition was set back to the initial condition (solvent B: solvent A: 10:90) in $55 \mathrm{~min}$ and allowed to run for another $10 \mathrm{~min}$, before the injection of another sample. Chromatographic separation was performed on a ChromCloneTM C18 column $(5 \mu \mathrm{m}$ particle size, $250 \times 4.6 \mathrm{~mm})$, and the detection was conducted using a diode-array UV detector at $254 \mathrm{~nm}$ [9].

Standard solution of gallic acid, ellagic acid, rutin, and luteolin was prepared in methanol $(0.1 \mathrm{mg} / \mathrm{mL})$. The sample solution was prepared by dissolving $1 \mathrm{mg}$ of TOF extract in 1 of $\mathrm{mL}$ methanol. Both the standard and sample solutions were filtered through a Whatman $0.45 \mu \mathrm{m}$ syringe filter. The responses were measured as peak areas versus concentration.

\subsection{Antibacterial Activity}

2.4.1. Bacterial Strains. Antibacterial activity of $P$. granatum extracts was determined against Gram-positive bacteria (Staphylococcus aureus) and Gram-negative bacteria (Escherichia coli). Extracts were tested against bacterial strains obtained from the American Type Culture Collection (S. aureus ATCC 25923 and E. coli ATCC 25922) and clinical isolates strains obtained from the department of microbiology (University Hospital of Monastir) with resistance profile described in Table 1.

Antibiotic modulation activity was determined against resistant strains: penicillin-resistant $S$. aureus, methicillin- 
TABle 1: Phenotypic resistance profile of clinical isolates bacterial strains.

\begin{tabular}{|c|c|c|c|}
\hline Bacterial strains & Clinical sample & Resistance to antibiotics & Phenotypic resistance profile \\
\hline \multirow{4}{*}{ Staphylococcus aureus } & Ascitic fluid & Penicillin G & Penicillin-resistant S. aureus \\
\hline & & Penicillin G & \multirow{3}{*}{ Methicillin-resistant S. aureus } \\
\hline & Pus & Oxacillin & \\
\hline & & Cefoxitin & \\
\hline \multirow{19}{*}{ Escherichia coli } & \multirow{5}{*}{ Urine } & Amoxicillin & \multirow{5}{*}{ Penicillin-resistant $E$. coli } \\
\hline & & Ticarcillin & \\
\hline & & Piperacillin & \\
\hline & & Amoxicillin + clavulanic acid & \\
\hline & & Ticarcillin + clavulanic acid & \\
\hline & \multirow{14}{*}{ Urine } & Amoxicillin & \multirow{14}{*}{ Multidrug-resistant E. coli } \\
\hline & & Ticarcillin & \\
\hline & & Ceftazidime & \\
\hline & & Ticarcillin + clavulanic acid & \\
\hline & & Piperacillin & \\
\hline & & Cefotaxime & \\
\hline & & Cefalotin & \\
\hline & & Amoxicillin + clavulanic acid & \\
\hline & & Gentamycin & \\
\hline & & Tobramycin & \\
\hline & & Ciprofloxacin & \\
\hline & & Ofloxacin & \\
\hline & & Norfloxacin & \\
\hline & & Rifamycin & \\
\hline
\end{tabular}

resistantS. aureus, penicillin-resistant E. coli, and multidrugresistant E. coli.

2.4.2. Disc Diffusion Method. The disc diffusion method was performed according to the method reported by the $\mathrm{Na}$ tional Committee for Clinical Laboratory Standards (NCCLS). Sterile paper disks of $6 \mathrm{~mm}$ diameter were impregnated with different extracts and then air-dried. Each disk contains approximately $20 \mu \mathrm{L}$ of extract at the concentration of $5 \mathrm{mg} / \mathrm{mL}$. Blank disks, impregnated with solvents, were used as a negative control. These paper discs were placed on Müller-Hinton agar inoculated with the tested bacteria $\left(10^{8} \mathrm{CFU} / \mathrm{mL}\right)$. Following incubation at $37^{\circ} \mathrm{C}$ for 24 hours, diameters of inhibition zones were measured in millimeter scale.

2.4.3. Microdilution Method. The microdilution method using 96-well microplates and 3-(4,5-dimethylthiazol-2-yl)2,5-diphenyltetrazolium bromide (MTT) to indicate bacterial growth was used to determine the Minimal Inhibitory Concentration (MIC) $[10,11]$. An inoculum of $100 \mu \mathrm{L}$ of each strain suspended in Müller-Hinton broth up to a final concentration of $10^{6} \mathrm{CFU} / \mathrm{mL}$ was used in 96-well microplates. Each well received $100 \mu \mathrm{L}$ of each extract solution. Using twofold serial dilutions, the final concentrations of the extracts varied from 5 to $0.04 \mathrm{mg} / \mathrm{mL}$. After incubation at $37^{\circ} \mathrm{C}$ for 24 hours, $40 \mu \mathrm{L}$ of MTT at the concentration of $0.2 \mathrm{mg} / \mathrm{mL}$ was added to each well. After incubation for 30 minutes, MICs, which are the lowest concentrations required to inhibit growth, were recorded as the lowest concentrations required to inhibit the color change of the bacterial suspension to blue.
2.5. Antibiotic Modulation. The checkerboard method, which is commonly used for the determination of synergy between the antibiotics and natural antibacterials, was used for the antibiotic modulation assay [12]. This method is combined with a calculation of a fractional inhibitory concentration (FIC) index. To evaluate the synergy of our extracts with amoxicillin and cefotaxime, we started by determining the MIC of these antibiotics $\left(\mathrm{MIC}_{\mathrm{ATB}}\right)$ and the MIC of our extracts $\left(\mathrm{MIC}_{\mathrm{Ext}}\right)$ alone, and then we determined their new MIC after combination (MIC' ${ }_{\text {ATB }}$ and MIC' $_{\text {Ext }}$ ). FIC must be determined to judge the interaction between the antibiotic and the natural extract:

$\mathrm{FIC}=\mathrm{FIC}_{\mathrm{A}}+\mathrm{FIC}_{\mathrm{B}}$ with $\mathrm{FIC}_{\mathrm{A}}=\mathrm{MIC}_{\mathrm{ATB}} / \mathrm{MIC}_{\mathrm{ATB}}$ and $\mathrm{FIC}_{\mathrm{B}}=\mathrm{MIC}_{\text {Ext }} / \mathrm{MIC}_{\mathrm{Ext}}$

"Synergy" was defined by an FIC index $\leq 0.5$. When the FIC index fell between 0.5 and 4.0 , it indicated that there was "no interaction" between the agents. An FIC index $=4.0$ would indicate that there was an "antagonism" between the two agents.

The microdilution method using tetrazolium salt [10] was used to determine the MIC of plant extracts and MIC of amoxicillin and cefotaxime. The initial concentrations of the agents used were determined according to their MIC value and then were serially diluted in twofold steps.

\section{Results and Discussion}

3.1. Phytochemical Study. In this study, six extracts were prepared from the powdered leaves of $P$. granatum. The yield of extracts depended on extraction solvents and extraction methods and varied from 0.5 to $20.07 \%$ (Table 2). The highest extraction yield was obtained with the aqueous extract and the lowest yield was obtained with the ethyl acetate extract. 
TABLE 2: Extraction yields, total contents of phenols, flavonoids, and tannins of extracts from P. granatum leaves.

\begin{tabular}{|c|c|c|c|c|c|c|}
\hline & \multicolumn{6}{|c|}{ Extracts } \\
\hline & $\begin{array}{l}\text { Hexane } \\
\text { extract }\end{array}$ & $\begin{array}{c}\text { Chloroform } \\
\text { extract }\end{array}$ & Ethyl acetate extract & Ethanol extract & Aqueous extract & TOF extract \\
\hline Extraction yield (\%) & 0.50 & 1.33 & 0.74 & 6.36 & 20.07 & 2.17 \\
\hline Phenols mg GAE/g DM & ND & $49.24 \pm 5.65$ & $122.98 \pm 1.27$ & $238.63 \pm 3.23$ & $262.98 \pm 5.11$ & $382.27 \pm 6.46$ \\
\hline Flavonoids mg QE/g DM & ND & ND & $55.11 \pm 5.92$ & $231.77 \pm 14.81$ & $287.33 \pm 15.55$ & $492.88 \pm 19.25$ \\
\hline Tannins mg TAE/100 g DM & ND & $30.68 \pm 0.91$ & $56.13 \pm 2.32$ & $96.81 \pm 2.27$ & $125.92 \pm 3.9$ & $86.46 \pm 2.1$ \\
\hline
\end{tabular}

ND: not detected.

The preliminary phytochemical study showed the presence of flavonoids and hydrolysable tannins in ethanol extract, aqueous extract, and TOF extract. Our results are comparable to the previous findings that identified phenolic acids, flavonoids, and hydrolysable tannins in $P$. granatum leaves [13-15]. But, some reports found, in addition to flavonoids and tannins, other secondary metabolites such as alkaloids [16] and anthocyanins [17].

Based on the results of the preliminary phytochemical study, the total contents of phenols, flavonoids, and tannins in leaf extracts of $P$. granatum were determined. These results are shown in Table 2. The TOF contained the highest value of phenols $(382.27 \pm 6.46 \mathrm{mg}$ GAE/g DM) and flavonoids $(492.88 \pm 19.25 \mathrm{mg} \mathrm{QE} / \mathrm{g} \mathrm{DM})$, followed by the aqueous extract $(262.98 \pm 5.11 \mathrm{mg} \quad \mathrm{GAE} / \mathrm{g} \quad \mathrm{DM}$ and $287.33 \pm 15.55 \mathrm{mg} \mathrm{QE} / \mathrm{g} \mathrm{DM}$, respectively). The aqueous extract showed the highest content of tannins $(125.92 \pm 3.9 \mathrm{mg}$ TAE/100 g DM) followed by the ethanol extract $(96.81 \pm 2.27 \mathrm{mg}$ TAE/100 g DM). Phenols, flavonoids, and tannins were absent in hexane extract. We also did not find flavonoids in chloroform extract. Polar extracts are richer in different secondary metabolites than nonpolar extracts. In fact, the phenolic nature of polyphenols such as flavonoids and tannins makes them relatively hydrophilic and highly soluble in water and polar organic solvents such as methanol, ethanol, and acetonitrile, or their mixture of water [18]. TOF contained the highest value of phenols and flavonoids but contained fewer tannins since it has been obtained using purification methods that removed tannins and enriched the extract with flavonoids. The total contents of phenols (410.85 $\pm 10.15 \mathrm{mg}$ GAE/g DM) and flavonoids $(286.88 \pm 20.73 \mathrm{mg} \mathrm{QE} / \mathrm{g} \mathrm{DM})$ in our study are greater than those reported by [17] which are $289.76 \pm 1.55 \mathrm{mg}$ GAE/g $\mathrm{DM}$ and $82.6 \pm 2.67 \mathrm{QE} / \mathrm{g} \mathrm{DM}$, respectively, in extracts obtained by successive extraction using cold maceration method with solvents of increasing polarity (hexane, dichloromethane, ethyl acetate, ethanol, and methanol). Such a difference may be explained by the extraction method and the harvest time. Indeed, we prepared our extracts by successive extraction using the Soxhlet apparatus which gives better efficiency than cold maceration. Soxhlet method uses a fresh solvent that is always provided to the sample causing maximum analyte solubility [19]. Harvest time has an influence on the amount of phenols and flavonoids. Total levels of phenolics and flavonoids in pomegranate leaves are low in the early stages of leaf growth and then increased gradually until the end of September [16]. Regarding tannins assay, we found the highest values in polar extracts (aqueous extract, ethanol extract). Tannins are usually extracted from natural tissues by aqueous solutions of methanol, ethanol, or acetone, as well as ethyl acetate. Nonpolar organic solvents (hexane, chloroform, and dichloromethane) have low extraction strength for tannins [20].

Two flavonoids and two phenolic acids were determined by HPLC analysis of TOF extract (Figure 1). The flavonoids are rutin $(3.56 \pm 0.11 \mathrm{mg} / \mathrm{g})$ and luteolin $(0.81 \pm 0.031 \mathrm{mg} / \mathrm{g})$. The phenolic acids are gallic acid $(9.65 \pm 0.092 \mathrm{mg} / \mathrm{g})$ and ellagic acid $(8.56 \pm 1.54 \mathrm{mg} / \mathrm{g})$. The chromatogram also contained other unidentified peaks.

It has been reported that $P$. granatum leaf contains phenolic acids (gallic acid and ellagic acid), flavonoids (apigenin, luteolin, rutin, etc.), and hydrolysable tannins (punicafolin, corilagin, granatin, etc.) [13-15, 21].

3.2. Antibacterial Activity. The antibacterial activity of $P$. granatum extracts was assayed in vitro by agar disc diffusion method and microdilution method against Gram-positive and Gram-negative human pathogenic bacteria. Table 3 summarizes the microbial growth inhibition of different extracts. The in vitro antibacterial study against the standard and resistant strains of $S$. aureus and $E$. coli showed that $P$. granatum leaf extracts exhibited various levels of antibacterial effect against all tested bacterial strains. Both techniques, disc diffusion and microdilution, have given consistent results. The inhibition zone diameters varied from 8 to $19 \mathrm{~mm}$ and MIC values varied from 0.625 to over $5 \mathrm{mg} /$ $\mathrm{mL}$. The TOF extract was the most active against all tested strains. In fact, this extract showed a remarkable activity against the Gram-positive and Gram-negative standard strains $(\mathrm{MIC}=0.625 \mathrm{mg} / \mathrm{mL})$ and the penicillin-resistant strains $(\mathrm{MIC}=2.5 \mathrm{mg} / \mathrm{mL})$. It also displayed an interesting activity against the methicillin-resistant $S$. aureus ( $\mathrm{MIC}=1.25 \mathrm{mg} / \mathrm{mL}$ ) which is a major nosocomial pathogen worldwide and only some antibiotics such as vancomycin and teicoplanin are active against it [22]. The ethanol extract was active against all $S$. aureus strains and standard E. coli strains $(\mathrm{MIC}=2.5 \mathrm{mg} / \mathrm{mL})$. The aqueous extract was especially active against $E$. coli standard strain $(\mathrm{MIC}=1.25 \mathrm{mg} /$ $\mathrm{mL}$ ) and $S$. aureus standard strain $(\mathrm{MIC}=2.5 \mathrm{mg} / \mathrm{mL})$.

This antimicrobial activity can be assigned to tannins and flavonoids found in $P$. granatum leaf extracts. These phytochemical groups are known to possess antimicrobial compounds $[23,24]$. Their presence in the plant extracts could, therefore, justify the observed activity especially with the TOF extract, aqueous extract, and the ethanol extracts 


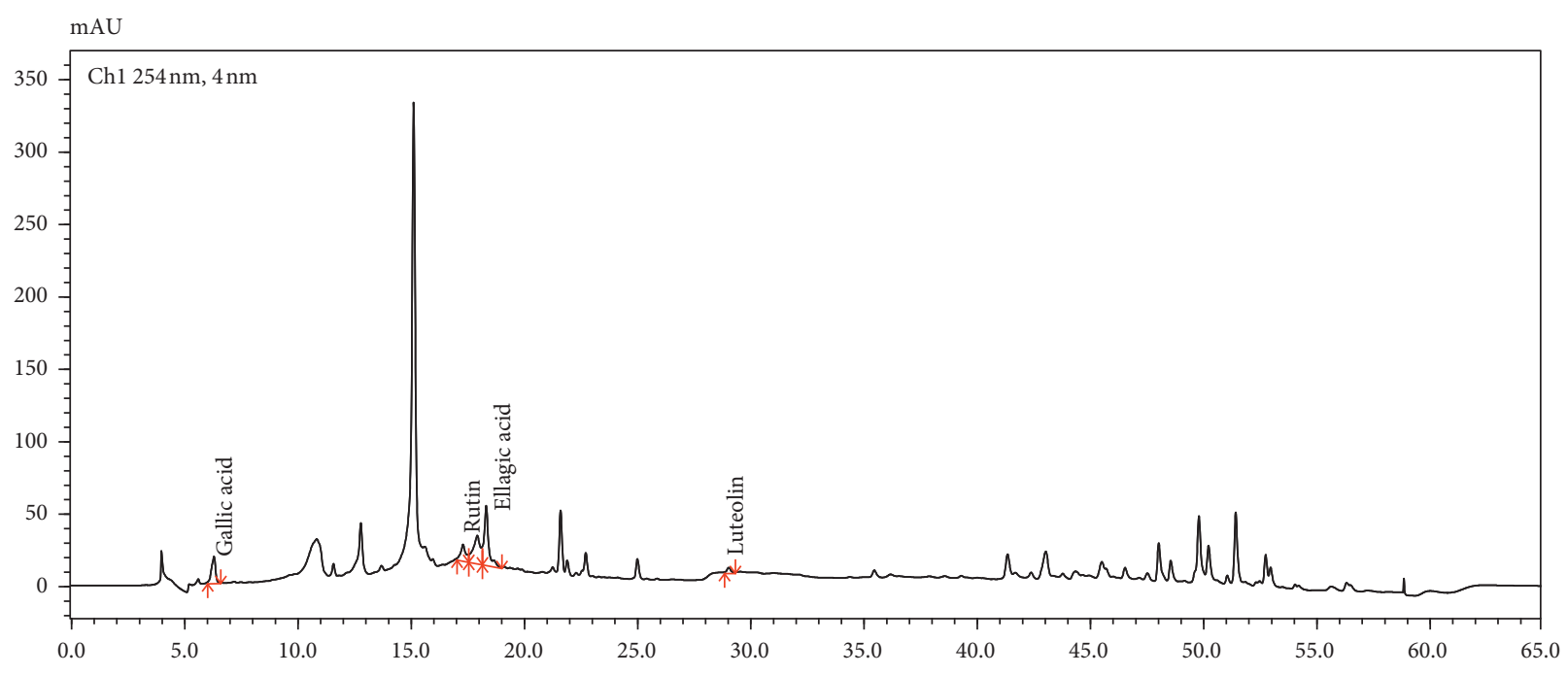

FIgURE 1: HPLC chromatogram of TOF extract of Punica granatum leaves.

TABle 3: Antibacterial activity of $P$. granatum leaf extracts by microdilution method: Minimal Inhibitory Concentration was expressed in $\mathrm{mg} / \mathrm{mL}$ (diameters of inhibition zones were measured in millimeter scale).

\begin{tabular}{|c|c|c|c|c|c|c|}
\hline \multirow[b]{2}{*}{ Extract } & \multicolumn{3}{|c|}{ Staphylococcus aureus } & \multicolumn{3}{|c|}{ Escherichia coli } \\
\hline & $\begin{array}{c}\text { Standard strain } \\
\text { ATCC } 25923\end{array}$ & $\begin{array}{l}\text { Penicillin- } \\
\text { resistant strain }\end{array}$ & $\begin{array}{l}\text { Methicillin- } \\
\text { resistant strain }\end{array}$ & $\begin{array}{c}\text { Standard strain } \\
\text { ATCC } 25922\end{array}$ & $\begin{array}{l}\text { Penicillin- } \\
\text { resistant strain }\end{array}$ & $\begin{array}{l}\text { Multidrug- } \\
\text { resistant strain }\end{array}$ \\
\hline Hexane extract & $>5(-)$ & $>5(-)$ & $>5(-)$ & $>5(-)$ & $>5(-)$ & $>5(-)$ \\
\hline Chloroform extract & $5(-)$ & $>5(-)$ & $>5(-)$ & $2.5(-)$ & $2.5(-)$ & $5(-)$ \\
\hline Ethyl acetate extract & $5(-)$ & $>5(-)$ & $2.5(8)$ & $2.5(8)$ & $>5(-)$ & $5(-)$ \\
\hline Ethanol extract & $2.5(17)$ & $2.5(14)$ & $2.5(8)$ & $2.5(13)$ & $5(13)$ & $5(-)$ \\
\hline Aqueous extract & $2.5(19)$ & $5(15)$ & $5(10)$ & $1.25(13)$ & $5(14)$ & $5(12)$ \\
\hline TOF extract & $0.625(14)$ & $2.5(15)$ & $1.25(17)$ & $0.625(16)$ & $2.5(12)$ & $5(12)$ \\
\hline Amoxicillin & 0.001 & 0.064 & 0.128 & 0.001 & 0.256 & 0.512 \\
\hline Cefotaxime & 0.001 & 0.002 & 0.128 & 0.001 & 0.001 & 0.512 \\
\hline
\end{tabular}

which are the richest of polyphenols. The antimicrobial effects of pomegranate leaves were previously studied by the disk diffusion method. Indeed, these studies showed that the methanolic extract exhibited the best inhibition against all tested strains (Staphylococcus aureus, Bacillus cereus, Escherichia coli, Proteus mirabilis, and Salmonella typhi) [25]. Methanolic leaf extract of P. granatum also showed antibacterial activity against the predominant bacterial isolates of septic wounds that are multidrug-resistant $P$. aeruginosa, S. aureus, K. pneumoniae, and E. coli [26]. The antimicrobial activity of ethyl acetate extract of pomegranate leaves was also studied by the microdilution method and showed MIC of $3.75 \mathrm{mg} / \mathrm{mL}$ for $P$. aeruginosa, MIC of $7.5 \mathrm{mg} / \mathrm{mL}$ for E. coli, and MIC of $15 \mathrm{mg} / \mathrm{mL}$ for $S$. aureus [27].

3.3. Antibiotic Modulation. The potential reduction of antibiotic resistance by $P$. granatum extracts was carried out by calculation of the FIC index shown in Table 4 . The best synergistic interaction was found with TOF extract combined with amoxicillin for penicillin-resistant E. coli and penicillin-resistant $S$. aureus $(\mathrm{FIC}=0.125)$. TOF extract showed also synergistic effect with cefotaxime for methicillin-resistant $S$. aureus $(\mathrm{FIC}=0.5)$. The aqueous extract and ethanol extract were found to have a similar effect in reducing the resistance of penicillin-resistant $S$. aureus with amoxicillin $(\mathrm{FIC}=0.25)$. Chloroform extract and ethyl acetate extract showed no synergistic effect with amoxicillin and cefotaxime for all tested resistant strains.

In the interaction study, polar extracts such as TOF, ethanol, and aqueous extracts were found to be highly effective especially against penicillin-resistant strains. These extracts contained the highest amount of phenolic compounds such as flavonoids. In fact, many studies showed that, in synergy with antibiotics, phenolic compounds such as flavonoids, tannins, and phenolic acids pose a promising alternative for therapeutic strategies against drug-resistant bacteria. The proposed mechanisms of synergy were the copermeabilization of the bacterial membrane and the inhibition of penicillinase activity [28, 29]. The work [30] showed that pomegranate ethanol extract inhibited recombinant New Delhi metallo- $\beta$-lactamase 1 (NDM-1) activity and the $\mathrm{IC}_{50}$ value was $0.76 \mathrm{ng} / \mu \mathrm{L}$. The same extract caused an increase in NDM-1 E. coli cell permeability. In addition, methanol $P$. granatum leaf extract was able to produce a significant inhibition of biofilm formation for $L$. monocytogenes and S. aureus [31]. It should be noted that the 
TABle 4: Antibiotic modulation activity of P. granatum leaf extracts by checkerboard method (FIC index).

\begin{tabular}{|c|c|c|c|c|c|c|c|c|}
\hline \multirow{3}{*}{ Extract } & \multicolumn{4}{|c|}{ Staphylococcus aureus } & \multicolumn{4}{|c|}{ Escherichia coli } \\
\hline & \multicolumn{2}{|c|}{ Penicillin-resistant strain } & \multicolumn{2}{|c|}{$\begin{array}{l}\text { Methicillin-resistant } \\
\text { strain }\end{array}$} & \multicolumn{2}{|c|}{ Penicillin-resistant strain } & \multicolumn{2}{|c|}{ Multidrug-resistant strain } \\
\hline & Amoxicillin & Cefotaxime & Amoxicillin & Cefotaxime & Amoxicillin & Cefotaxime & Amoxicillin & Cefotaxime \\
\hline Chloroform extract & 1 & - & 2 & 2 & 1 & - & 2 & 1 \\
\hline Ethyl acetate extract & 2 & - & 2 & 2 & 1 & - & 2 & 1 \\
\hline Ethanol extract & 0.25 & - & 2 & 1 & 2 & - & 2 & 1 \\
\hline Aqueous extract & 0.25 & - & 2 & 1 & 0.5 & - & 2 & 0.5 \\
\hline TOF extract & 0.125 & - & 2 & 0.5 & 0.125 & - & 2 & 0.5 \\
\hline
\end{tabular}

formation of biofilm is an important mechanism of bacterial resistance. Finally, gallic acid, which is a phenolic acid present in TOF extract, showed a synergistic interaction with tetracycline by inhibiting the efflux pump in multidrugresistant E. coli [32]. To our knowledge, no study in literature measured the antibiotic modulation potential of pomegranate leaf extracts with $\beta$-lactam antibiotics.

\section{Conclusion}

The phytochemical preliminary screening of $P$. granatum leaf extracts showed the presence of hydrolysable tannins and flavonoids. The quantitative analysis of total phenolics, flavonoids, and tannins carried out with spectrophotometric methods had confirmed these results particularly with TOF, aqueous, and ethanol extracts. The antibacterial study showed that the TOF extract was the most active extract against all tested strains. The most important result was the activity shown by the former extract against the methicillinresistant Staphylococcus aureus. TOF extract also showed the best synergistic interaction with amoxicillin for penicillinresistant E. coli and penicillin-resistant S. aureus. HPLC determination of flavonoids and phenolic acids in TOF extract showed the presence of rutin, luteolin, gallic acid, ellagic acid, and other undetermined substances.

In conclusion, pomegranate leaf extracts or active compounds isolated from those extracts could be used to improve human health especially the prevention and treatment of infectious diseases and to fight the emergence and spread of resistant bacterial strains. Nevertheless, further researches are still needed to evaluate the mechanisms of action and toxicity of those extract.

\section{Data Availability}

The data used to support the findings of this study are included within the article.

\section{Conflicts of Interest}

The authors declare that they have no conflicts of interest.

\section{Acknowledgments}

This research was supported by the Ministry of Higher Education and Scientific Research of the Republic of Tunisia.

\section{References}

[1] World Health Organization, Antimicrobial Resistance: Global Report on Surveillance, World Health Organization, Geneva, Switzerland, 2014.

[2] H. Wagner and G. Ulrich-Merzenich, "Synergy research: approaching a new generation of phytopharmaceuticals," Phytomedicine, vol. 16, no. 2-3, pp. 97-110, 2009.

[3] N. Hasnaoui, M. Mars, J. Chibani, and M. Trifi, "Molecular polymorphisms in Tunisian pomegranate (Punica granatum L.) as revealed by RAPD fingerprints," Diversity, vol. 2, no. 1, pp. 107-114, 2010.

[4] K. Ghedira, R. Chemli, B. Richard, B. Zeches, and L. Le MenOlivier, "Contribution to the study of the traditional pharmacopea from Tunisia: study of the aerial parts of Ajuga iva (L.) schreb," Plantes Médicinales et Phytothérapie, vol. 25, no. 2-3, pp. 100-111, 1991.

[5] A. J. Harborne, Phytochemical Methods A Guide to Modern Techniques of Plant Analysis, Springer Science \& Business Media, Berlin, Germany, 1998.

[6] M. Ben Sghaier, W. Bhouri, A. Neffati et al., "Chemical investigation of different crude extracts from teucrium ramosissimum leaves. Correlation with their antigenotoxic and antioxidant properties," Food and Chemical Toxicology, vol. 49, no. 1, pp. 191-201, 2011.

[7] J. Boubaker, I. Skandrani, I. Bouhlel et al., "Mutagenic, antimutagenic and antioxidant potency of leaf extracts from nitraria retusa," Food and Chemical Toxicology, vol. 48, no. 89, pp. 2283-2290, 2010.

[8] S. Kilani-Jaziri, W. Bhouri, I. Skandrani, I. Limem, L. ChekirGhedira, and K. Ghedira, "Phytochemical, antimicrobial, antioxidant and antigenotoxic potentials of Cyperus rotundus extracts," South African Journal of Botany, vol. 77, no. 3, pp. 767-776, 2011.

[9] T. Seal, "Quantitative HPLC analysis of phenolic acids, flavonoids and ascorbic acid in four different solvent extracts of two wild edible leaves, Sonchus arvensis and oenanthe linearis of north-eastern region in India," Journal of Applied Pharmaceutical Science, vol. 6, no. 2, pp. 157-166, 2016.

[10] J. Eloff, "A sensitive and quick microplate method to determine the minimal inhibitory concentration of plant extracts for bacteria," Planta Medica, vol. 64, no. 8, pp. 711-713, 1998.

[11] E. Grela, J. Kozłowska, and A. Grabowiecka, "Current methodology of MTT assay in bacteria-a review," Acta Histochemica, vol. 120, no. 4, pp. 303-311, 2018.

[12] K. Palaniappan and R. A. Holley, "Use of natural antimicrobials to increase antibiotic susceptibility of drug resistant bacteria," International Journal of Food Microbiology, vol. 140, no. 2-3, pp. 164-168, 2010.

[13] M. A. M. Nawwar, S. A. M. Hussein, and I. Merfort, "Leaf phenolics of Punica granatum," Phytochemistry, vol. 37, no. 4, pp. 1175-1177, 1994. 
[14] T. Tanaka, G.-I. Nonaka, and I. Nishioka, "Punicafolin, an ellagitannin from the leaves of Punica granatum," Phytochemistry, vol. 24, no. 9, pp. 2075-2078, 1985.

[15] M. A. M. Nawwar, S. A. M. Hussein, and I. Merfort, "NMR spectral analysis of polyphenols from Punica granatum," Phytochemistry, vol. 36, no. 3, pp. 793-798, 1994.

[16] L. Zhang, Y. Gao, Y. Zhang, J. Liu, and J. Yu, "Changes in bioactive compounds and antioxidant activities in pomegranate leaves," Scientia Horticulturae, vol. 123, no. 4, pp. 543-546, 2010.

[17] J. Bekir, M. Mars, J. P. Souchard, and J. Bouajila, “Assessment of antioxidant, anti-inflammatory, anti-cholinesterase and cytotoxic activities of pomegranate (Punica granatum) leaves," Food and Chemical Toxicology, vol. 55, pp. 470-475, 2013.

[18] R. Tsao, "Chemistry and biochemistry of dietary polyphenols," Nutrients, vol. 2, no. 12, pp. 1231-1246, 2010.

[19] M. D. Luque de Castro and F. Priego-Capote, "Soxhlet extraction: past and present panacea," Journal of Chromatography $A$, vol. 1217, no. 16, pp. 2383-2389, 2010.

[20] P. Arapitsas, "Hydrolyzable tannin analysis in food," Food Chemistry, vol. 135, no. 3, pp. 1708-1717, 2012.

[21] B. Fellah, M. Bannour, G. Rocchetti, L. Lucini, and A. Ferchichi, "Phenolic profiling and antioxidant capacity in flowers, leaves and peels of Tunisian cultivars of Punica granatum L," Journal of Food Science and Technology, vol. 55, no. 9, pp. 3606-3615, 2018.

[22] M. Michel and L. Gutmann, "Methicillin-resistant Staphylococus aureus and vancomycin-resistant enterococci: therapeutic realities and possibilities," The Lancet, vol. 349, no. 9069, pp. 1901-1906, 1997.

[23] T. P. T. Cushnie and A. J. Lamb, "Antimicrobial activity of flavonoids," International Journal of Antimicrobial Agents, vol. 26, no. 5, pp. 343-356, 2005.

[24] K.-T. Chung, T. Y. Wong, C.-I. Wei, Y.-W. Huang, and Y. Lin, "Tannins and human health: a review," Critical Reviews in Food Science and Nutrition, vol. 38, no. 6, pp. 421-464, 1998.

[25] H. Chaitra, M. Madhuri, T. N. Swaroop, D. Arijit, B. Sourav, and K. C. Rohit, "Evaluation of antimicrobial properties, phytochemical contents and antioxidant capacities of leaf extracts of Punica granatum L." Research Journal of Biological Sciences, vol. 1, no. 2, pp. 32-37, 2012.

[26] R. R. Pallavali, S. Avula, V. L. Degati, M. Penubala, A. G. Damu, and V. R. P. Durbaka, "Data of antibacterial activity of plant leaves crude extract on bacterial isolates of wound infections," Data in Brief, vol. 24, 2019.

[27] R. Bisht, S. Chanyal, and P. K. Agrawal, "Antimicrobial and phytochemical analysis of leaf extract of medicinal fruit," Asian Journal of Pharmaceutical and Clinical Research, vol. 9, no. 4, pp. 131-136, 2016.

[28] M. Miklasińska-Majdanik, M. Kępa, R. D. Wojtyczka, D. Idzik, and T. J. Wąsik, "Phenolic compounds diminish antibiotic resistance of Staphylococcus aureus clinical strains," International Journal of Environmental Research and Public Health, vol. 15, no. 10, 2018.

[29] G. Eumkeb, S. Siriwong, S. Phitaktim, N. Rojtinnakorn, and S. Sakdarat, "Synergistic activity and mode of action of flavonoids isolated from smaller galangal and amoxicillin combinations against amoxicillin-resistant Escherichia coli," Journal of Applied Microbiology, vol. 112, no. 1, pp. 55-64, 2012.

[30] B. Chandar, S. Poovitha, K. Ilango, R. MohanKumar, and M. Parani, "Inhibition of New Delhi metallo- $\beta$-lactamase 1 (NDM-1) producing Escherichia coli IR-6 by selected plant extracts and their synergistic actions with antibiotics," Frontiers in Microbiology, vol. 8, 2017.

[31] A. Nostro, A. Guerrini, A. Marino et al., "In vitro activity of plant extracts against biofilm-producing food-related bacteria," International Journal of Food Microbiology, vol. 238, pp. 33-39, 2016.

[32] G. R. Dwivedi, N. Tiwari, A. Singh et al., "Gallic acid-based indanone derivative interacts synergistically with tetracycline by inhibiting efflux pump in multidrug resistant E. Coli," Applied Microbiology and Biotechnology, vol. 100, no. 5, pp. 2311-2325, 2016. 